\title{
THBS1 Overexpression Positive
}

National Cancer Institute

\section{Source}

National Cancer Institute. THBS1 Overexpression Positive. NCI Thesaurus. Code C158109.

An indication that overexpression of THBS1 has been detected in a sample. 